\author{
Robert Tyrata \\ Universidad Pontificia Juan Pablo II de Cracovia \\ Academia de Música de Cracovia \\ Federación Internacional de Pueri Cantores
}

\title{
La Música litúrgica en la reflexión sobre el Misterio Pascual
}

El 16 de enero de 1988 la Congregación vaticana para el Culto Divino emitió una carta circular relativa a la „preparación y celebración de las Fiestas de Pascua". La carta precisó muchas cuestiones referentes al modo de celebrar los días más importantes en la vida de la Iglesia, ya sea desde el punto de vista de la liturgia, y con ella de la música, ya sea prestando atención a las tradiciones y usos presentes en los países del mundo. En el período litúrgico que nos interesa se habla de acontecimientos especiales. La carta lo precisa de la siguiente manera:

La Iglesia celebra cada año los grandes misterios de la redención humana desde la misa vespertina del jueves en la cena del Señor, hasta las vísperas del domingo de resurrección. Este espacio de tiempo se llama justamente el „triduo del crucificado, del enterrado y del resucitado ${ }^{1}$.

La misma denominación „Triduo Pascual” apareció en el año 1929 y se difundió a partir de las reformas litúrgicas emprendidas ya por el papa Pio XII. La expresión „Triduo" no se puede traducir por "tres días” y no se trata ni siquiera de enumerar las horas. Se trata, por decirlo así, de tres etapas: banquete de despedida y así como tiempo profético del sacrificio de la cruz, la muestre en la cruz, el reposo en el sepulcro y la resurrección. Históricamente estas celebraciones tienen

1 Carta circular de la Congregación para el Culto Divino Preparación y celebración de las fiestas pascuales, n. 38 [abrev.: LO]; trad. en lengua polaca in: "Kielecki Przegląd Diecezjalny" 64 (1988) 4, pagg. 229-243 (in seguito indicato con la sigla LO); Congregatio pro Culto Divino, Letterae circulares Paschalis sollemnitatis. Preparazione e celebrazione delle feste pasquali (16 I 1988): testo latino en "Notitiae" 24 (1988) 81-107. Traduzione polacca in "Ruch Biblijny i Liturgiczny” 5 (1988) 369-391. 
origen en la liturgia de Jerusalén Una descripción detallada del Triduo la podemos encontrar ya en el „Diario” de la peregrina Egeria²

\section{Importancia de la música en general en los ritos del Triduo Pascual}

En el documento vaticano se dedica un espacio bastante importante para recordar que durante el Triduo la oración de la mañana debe ser celebrada de forma solemne (interpretada con canto).

Se recomienda la celebración comunitaria del oficio de la lectura y de las laudes matutinas del viernes de la pasión del Señor y también del sábado santo. Conviene que participe el obispo, a ser posible en la iglesia catedral, con el clero y el pueblo ${ }^{3}$.

Es particularmente importante que todas las oraciones sean cantadas:

el canto del pueblo, de los ministros y del sacerdote celebrante reviste una importancia particular en la celebración de la semana santa y especialmente del Triduo Pascual, porque está más de acuerdo con la solemnidad de estos días y también porque los textos obtienen una fuerza mayor cuando van acompañados del cantón

Por esta razón, se anima tenazmente a las conferencias episcopales a preparar melodías para los textos y las aclamaciones. Se trata especialmente de los siguientes textos: la oración universal del viernes santo, el canto para mostrar la cruz, las aclamaciones en la procesión con el cirio pascual, el canto del pregón pascual, la aclamación después de la bendición del agua. Se llama la atención sobre la importancia de los cantos de procesión, como entre otros: los cantos para la procesión con las palmas, los salmos responsoriales. Es indispensable llamar la atención sobre la preparación de las melodías para la Pasión del Señor ejecutada con canto 5 . También es muy importante que: "en las iglesias mayores se interprete el tesoro abundante de la música sacra, ya sea antigua o moderna; sin embargo siempre

2 Ver B. Nadolski, Liturgika, vol. 2, Liturgia i czas (trad. Liturgia y Tiempo), Poznań 1991, pag. 65.

3 LO 40.

${ }^{4}$ LO 42.

5 Ver LO 42. 


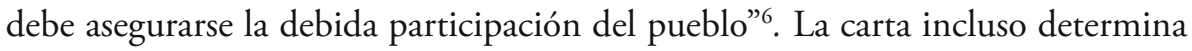
de forma explícita que

si en alguna hora y en algún lugar resulta insuficiente el número de participantes, de ministros y de cantores, que las celebraciones del triduo pascual sean omitidas y que los fieles se reúnan en alguna iglesia más grande 7 .

Después de haber presentado el significado jurídico y teológico, así como el desarrollo de las celebraciones litúrgicas con la consideración por la música litúrgica, me permito referirme a proposiciones musicales concretas que practicamos en la catedral real de Cracovia. Es una práctica elaborada ya desde hace algunos años.

\section{Misa en la Cena del Señor}

La liturgia en la Cena del Señor es un momento singular en el cual la Congregación destaca la gran importancia de la música litúrgica. En primer lugar:

según las costumbres locales, durante el canto del himno "Gloria a Dios" se tocan las campanas. Terminado el canto, ya no se tocarán hasta el "Gloria a Dios" de la vigilia pascual [...]. Durante este tiempo el órgano y los demás instrumentos musicales se pueden usar sólo para sostener el canto ${ }^{8}$.

Existe sin embargo la tradición de no usar en absoluto durante este período las campanas, las campanitas, la música de órgano y aparecen las llamadas matracas.

Esta costumbre se remonta a la época carolingia. Amalarico de Metz veía en ella un signo de imitación de la humildad de que dio prueba Jesús. En la misma se encuentra una referencia a los tiempos, cuando en la liturgia no se usaban las campanas o instrumentos?.

Se puede hablar también de un específico „ayuno” para los oídos. A continuación se señala que para la procesión de las ofrendas se debería cantar el canto

\footnotetext{
6 LO 42.

7 LO 43.

8 LO 50.

9 B. Nadolski, Liturgika, pag. 67.
} 
Donde hay caridad verdadera ${ }^{10}$. En la tradición este canto estaba relacionado con el rito del lavatorio de los pies a los discípulos, el llamado mandatum, porque este canto se interpretaba durante la entrega de la comida ${ }^{11}$. El canto siguiente en la carta circular es el canto para la procesión al altar con el que se acompaña el Santísimo Sacramento al lugar de la reposición, terminada la liturgia. El documento constata que en este momento se interpreta el canto Pange lingua ${ }^{12}$.

La antífona de entrada se presenta del siguiente modo: "No debemos gloriarnos en otra cosa que en la cruz de Jesucristo, nuestro Señor. Él es nuestra salvación, nuestra vida y nuestra resurrección; por medio de él hemos sido salvados y liberados" (Gal 6,14), por esta razón propongo al inicio de la liturgia el canto dedicado a la Cruz, cantado por todos los fieles y cuyo título es Cruz santa, por encima de cualquier árbol ${ }^{13}$, después viene el motete cantado por el coro: In monte Oliveti de Mikołaj Zieleński. Durante el lavatorio de los pies cantamos con los fieles el canto Donde hay verdadero amor y después el coro canta Ubi Caritas et Amor de Maurice Durufle. Si hace falta cantamos con los fieles Os doy un mandamiento nuevo ${ }^{14}$. Para la preparación de las ofrendas el coro canta el motete de Tomás Luis

${ }^{10}$ LO 52.

${ }^{11}$ Ver B. Nadolski, Liturgika, pag. 66.

${ }^{12} \mathrm{LO} 54$.

${ }^{13}$ La primeras cuatro estrofas son una traducción del fragmento del himno de Venanzio Fortunato del siglo VI Pange, lingua ("Pange, lingua, gloriosi Lauream [proelium] certaminis") (hago notar que las palabras iniciales se pueden confundir con el himno de Santo Tomás, por ello indico la cita más larga); en la tradición polaca se usa el texto y la música provenientes del siglo XVI. El canto se encuentra en el Cantoral sacro de don Michał M. Mioduszewski CM (Cracovia 1838). Este es el texto del canto: “¡Santa Cruz, árbol único en nobleza! En ningún bosque se encuentra otro igual, único, en el cual está Dios mismo; Dulce árbol, dulces clavos, que llevan un fruto delicioso; inclina las ramas árbol santo, ¡da alivio a los miembros extendidos! Cambia ahora tu innata severidad; baja ligera y silenciosamente el Cuerpo del Rey Celestial. Sólo tú trajiste la salvación del mondo; Per medio de ti se ha reparado el camino, para el mundo que se había extraviado; sobre el cual la Sangre que brotaba del Cordero se extendió; Es una gran bondad para cualquiera morir en la cruz".

${ }^{14}$ El canto Os doy un nuevo mandamiento - el texto del estribillo se refiere a Jn 13, 34, el texto de las estrofas a 1 Cor 13. La música del estribillo ha sido compuesta por Zofia Jasnota, la música de las estrofas por don Zdzisław Bernat. El canto aparece en el Cantoral sacro de don Jan Siedlecki de 1973. El texto del canto se presenta de la siguiente manera: "Estr. Os oy un nuevo mandamiento: que os améis los unos a los otros; Si hablase las lenguas de los hombres y de los ángeles, pero no tuviese amor, sería como el metal que resuena o una campana que repica. Si tuviese el don de profecía y conociese todos los misterios y toda la ciencia y tuviese la fe necesaria para mover los montes, pero no tuviese amor, yo no sería nada. Si repartiese todos mis bienes para alimentar a los pobres, si diese mi cuerpo para ser quemado, y no tuviese amor, no me serviría de nada. El amor es paciente, es bondadoso; el amor no tiene 
da Vittoria Jesu dulcis memoria, sucesivamente cantamos con los fieles el canto Recibe, Señor, de las manos del sacerdote ${ }^{15}$. La antífona de la comunión se presenta de la manera siguiente: "Este es mi cuerpo entregado por vosotros, * este es el cáliz de mi sangre para la Nueva Alianza. * Haced esto siempre que lo toméis, * en memoria mía (1 Cor 11, 24. 25)". Por esto comenzamos este rito cantando con los fieles $O h$ preciosisima Sangre ${ }^{16}$. A continuación el coro canta $O$ salutaris Hostia de Gioachino Rossini. Si hace falta cantamos después con los fieles el canto $E l$ Señor ha preparado el cenáculo ${ }^{17}$. Durante el trasporte del Santísimo Sacramento a la capilla de la adoración, el coro canta el canto Adoro te, devote con una elaboración polifónica, después los fieles cantan el canto Pange lingua. Toda la oración se termina con el coro que canta el motete de Joseph Haydn Tristis est anima mea.

envidia; el amor no es jactancioso, no se envanece, no hace nada indebido, no busca el proprio interés, non se irrita, no guarda rencor, no se goza de la injusticia, sino que goza de la verdad".

${ }^{15}$ Es una parte de los llamados cantos de la misa, es decir de los cantos que explican cada una de las partes de la santa misa. El conjunto de los cantos tiene por título Dios. Tu pueblo. En la versión original era la quinta estrofa sucesiva del canto interpretado con una única melodía, en lugar de la dievsrsas estrofas que eran dedicadas a: 1. Entrada, 2. Gloria, 3. Evangelio, 4. Credo, 5. Ofertorio etc. El autor del texto es Henryk Felsztyński. El texto aparece impreso en el cantoral: Tomasz Kunzek, Pieśni kościelne (trad. Cantos sacros), Lwów 1859, mientras que aparece en el Cantoral que contiene los cantos sacros de don Jan Siedlecki (Cracovia 1895). Este es el texto de la segunda estrofa para la preparación de las ofrendas: "De las manos del sacerdote recibe, oh Señor, esta ofrenda de pan y vino que se convertirán para nosotros en el Cuerpo y la Sangre de tu Hijo; Que lave nuestros crímenes y calme tu ira, oh Señor. Que nos una al cielo y nos obtenga el perdón”.

${ }^{16}$ El canto Oh preciosísima Sangre, oh Sangre de la redención - el texto de este canto aparece en el Cantoral Eucarístico (Lwów 1884), en cambio la melodía está en Cantoral que contiene los cantos sacros de don Jan Siedlecki (Cracovia 1908). El texto del canto es el siguiente: "Oh preciosísima Sangre, oh Sangre de la redención, bebida de vida, ique nos ha sido dada del cielo! Oh fuente de gracia, oh precio de la salvación, ¡Tú curas las heridas del pecado! ¡Tú estás encerrado en el cáliz de Jesús, para que nos llene a todos de vida, para que, Sangre Divina Santísima, obtenga misericordia para el mundo!”.

${ }^{17}$ El canto El Señor ha preparado el Cenáculo - el texto ha sido escrito por sor M. Imelda Kosmala CSSF, mientras que la melodía ha sido compuesta por Tomasz Kiesewetter. El canto aparece en el Cantoral sacro de don Jan Siedlecki (Cracovia 1987). El texto del canto es el siguiente: „Estr. El Señor ha preparado el Cenáculo, invita a su pueblo. Para todos nosotros ha abierto la casa y ha puesto la mesa. Venid, de los caminos y pueblos, porque pasa el tiempo. Venid, enfermos y pobres, el Señor os curará. Todos tienen un lugar reservado en la casa del Señor. Que no falte nadie, se celebra el banquete del Señor. Acerquémonos dando gracias, alimentémonos con el pan, bebamos la bebida de los inmortales para tener la vida. Probad y ved el sabor de esta cena, de la abundancia de los dones de Dios tomad plenamente todas las gracias". 


\section{La Liturgia de la Pasión del Señor}

Es un día particular en el cual "la iglesia, por una antiquísima tradición, no celebra la eucaristía" ${ }^{\prime 1}$. Si ese día es necesario celebrar las exequias cristianas, hay que hacerlo sin canto y sin repique de campanas ${ }^{19}$. Un momento significativo de la liturgia es la presentación y adoración de la cruz. Respecto a esto, la Congregación presta una atención específica.

Que todo este rito se cumpla con el esplendor de dignidad que conviene a tal misterio de nuestra salvación: tanto la invitación hecha al mostrar la santa cruz, como la respuesta dada por el pueblo se hagan con el canto ${ }^{20}$.

A continuación se precisa: "durante la adoración de la cruz, se canten las antífonas, los «Improperios del Señor» y el himno, que recuerdan de modo lírico la historia de la salvación, o bien otros cantos adecuado" 21 . El rito del descubrimiento de la cruz ha sido enriquecido en la tradición de la Iglesia también con elementos como: antífona Crucem Tuam del siglo IX, que se cantaba desde el siglo $\mathrm{XI}$ en latín y en griego bajo el influjo de la liturgia bizantina. El canto siguiente es el Trishagion mencionado desde el concilio de Calcedonia (año 451), y como aclamación entró en la liturgia en el siglo V-VI. Y también los „improperios” ya mencionados en el documento vaticano. Se trata de acusaciones pronunciadas por Jesús, dirigidas al pueblo que no ha sabido ver las obras de Dios en la vida y en la pasión de Cristo. En la historia son conocidos dos tipos de Lamentos del Señor. A saber: Pueblo mio unidos a Trishagion y Ego te et tu. En los misales del siglo XV estas dos clases de Lamentos se unificaron. Y estas traducciones en lengua polaca constituyen textos estupendos desde el punto de vista literario. Estos textos son de origen veterotestamentario (libro de Amós y Miqueas) ${ }^{22}$. Santo Tomás de Aquino en cambio escribió el canto Pange lingua gloriosi que viene unido al rito de la adoración de la cruz. En la carta de la Congregación para el Culto Divino se indica también claramente que después de la adoración de la cruz el sacerdote celebrante canta la invitación a la oración del Señor que a continuación cantan $\operatorname{todos}^{23}$. No se puede entonces hablar de un recitado. El canto es una oración muy

\footnotetext{
${ }^{18}$ LO 59.

${ }^{19} \mathrm{LO} 61$.

${ }^{20} \mathrm{LO} 68$.

${ }^{21}$ LO 69.

${ }^{22}$ Ver B. Nadolski, Liturgika, pag. 69.

${ }^{23}$ Ver LO 70.
} 
especial. También es muy importante hacer referencia a la tradición popular de cada una de las Iglesias locales:

por su importancia pastoral, no descuidemos los actos de piedad, como el "via crucis", las procesiones de la pasión y el recuerdo de los dolores de la bienaventurada virgen María. Los textos y los cantos de estos ejercicios deben estar en armonía con el espíritu litúrgico ${ }^{24}$.

En la catedral de Wawel la música litúrgica interpretada durante la liturgia de la Pasión del Señor se articula de la siguiente forma. El texto de la Pasión del Señor se canta de forma solemne por tres cantores. Las invitaciones a la oración universal hechas por el diácono son interpretadas con el canto. El coro inicia la adoración de la cruz con los Improperi de Giovanni Pierluigi da Palestrina. Terminados estos, el coro canta la antífona Crucem Tuam de un compositor desconocido. A continuación empieza el canto de los fieles, los cuales cantan, bajo la dirección de la schola de los seminaristas, los cantos siguientes (todos relativos al tema de la Pasión): En la cruz el sufrimiento ${ }^{25}$ y Cruz de Cristo, seas alabada ${ }^{26}$. Sigue el coro de la catedral con la interpretación de Miserere de Gregorio Allegri. Durante la distribución de la santa comunión a los fieles el canto, normalmente, viene inicialmente interpretado por el coro de la catedral con la antífona Christus factus est pro nobis, y a continuación los fieles cantan Oh preciosisima Sangre ${ }^{27}$.

${ }^{24} \mathrm{LO} 72$.

${ }^{25}$ El canto En la cruz el sufrimiento - el autor del texto es don Karol Antoniewicz SJ, la melodía aparece en el Cantoral que contiene los cantos sacros de don Jan Siedlecki (Cracovia 1895). El texto del canto es el siguiente: "En la cruz el sufrimiento, en la cruz la salvación, en la cruz la enseńanza del amor. Quien a Ti, oh Dios, te comprenda una vez, ya no desea ni busca nada más. En la cruz el socorro, en la cruz el refresco, para el alma oscurecida por la tristeza. Quien adivina la cruz, su corazón no caerá lleno de dolor infinito; Cuando el sufrimiento, cuando la duda te queme hasta el fondo del corazón, cuando el rayo se acerque, ven a la cruz. Ella te sostendrá, te salvará; Si te han humillado o herido, o quizás el corazón ajeno te ha engañado, no desesperes, reza, perdona, que la cruz sea tu emblema”.

${ }^{26}$ El canto Cruz de Cristo seas alabada - el texto y la melodía de este canto aparecen en el Cantoral sacro de don Jan Siedlecki de 1959. Los fieles cantan las frases siguientes: "Cruz de Cristo seas alabada. Eternamente seas saludada, donde se ha cumplido la vida de Dios, Rey del mundo entero. Cruz de Cristo seas alabada. ¡Eternamente seas saludada! La misma Sangre te ha bañado, que nos ha lavado de nuestros pecados; Cruz de Cristo seas alabada. ¡Eternamente seas saludada! De Ti brota poder y fortaleza, en Ti está nuestra victoria”.

${ }^{27}$ El canto Oh preciosísima Sangre - el texto de este canto aparece en el Cantoral Eucarístico (Lwów 1884), en el lugar donde está la melodía en el Cantoral que contiene los cantos sagrados de don Jan Siedlecki (Cracovia 1908). El texto del canto es el siguiente: “¡Oh preciosísi- 
Para la acción de gracias todos los fieles cantan un canto muy popular en la Iglesia polaca: Alma de Cristo santifícame ${ }^{28}$. Cuando se traslada el Santísimo Sacramento a la capilla de la reserva, llamada también en Polonia „sepulcro divino”, el coro canta el motete de don Grzegorz Gerwazy Gorczycki Sepulto Domino. Después los fieles interpretan el canto: Jesucristo, Señor amado ${ }^{29}$. La oración cantada se termina con el canto por el coro de la catedral que canta Ecce Quomodo moritur iustus de Jacob Handl.

Fuera de la liturgia de la Pasión se cantan en Polonia Gorzkie żale (trad. Arrepentimientos amaros), una editorial creada el siglo XVIII, publicada con el título Snopek Mirry (trad. Mannello de Mirra) ${ }^{30}$. El texto y las melodías fueron compuestos por don Wawrzyniec Benik CM en Varsovia el año 1707. Es una oración cantada para conmemorar la pasión y la muerte de Jesucristo. En la

ma Sangre, oh Sangre de la redención, bebida de vida, dada a nosotros del cielo! Oh fuente de gracias, oh precio de la salvación, ¡Tú curas las heridas del pecado! ¡Tú te has encerrado en el cáliz de Jesús, para que nos colmes a todos de vida, para que en el mundo, santísima Sangre Divina, implores misericordia! Oh preciosísima Sangre, a través del corazón limpísimo, donde tenías tu fuente en esta tierra, a Ti rendimos honor, eternamente gracias con los ángeles, con los santos".

${ }^{28}$ El canto Alma di Cristo - el texto es la traducción de la oración de San Ignacio de Loyola, Anima Christi del siglo XVI. La melodía compuesta por Stefan Stuligrosz aparece en el Cantoral sacro de don Jan Siedlecki del 1973. El texto del canto es el siguiente: "Alma de Cristo, santifícame. Cuerpo de Cristo, sálvame. Sangre de Cristo, embriágame. Agua del costado de Cristo, lávame. Pasión de Cristo, confórtame. Oh buen Jesús, óyeme. Dentro de tus llagas escóndeme. No permitas que me separe de ti. Del enemigo maligno defiéndeme. En la hora de mi muerte llámame. Haz que yo venga a alabarte con tus santos por los siglos de los siglos. Amen".

29 El canto „Jesucristo, Señor amado” - el autor del texto escrito en 1610 es Abraham Różniatowski. Al parecer aparece junto con la melodía en el Cantoral sacro de don Michał M. Mioduszewski CM (Cracovia 1838). El texto del canto escrito por Różniatowski en 1610 es el siguiente: "Jesucristo, Señor amado, oh Cordero tan paciente, has alzado, has alzado tus manos en la cruz quitando, quitando mi deshonestidad. Llora por Él, hombre miserable, mirando cuán misericordioso es. Jesús, Jesús muere en la cruz, el sol, el sol cubre su luz. El Señor ha pronunciado las últimas palabras, la cabeza Le cae sobre el pecho. La Madre, la Madre dolorosa está al pie de la cruz, con tristeza casi sin vida. Al final Le atraviesan el costado, con agua sale abundante la sangre. Nuestro arrepentimiento, nuestro arrepentimiento expresamos hoy con lágrimas, Jesús, Jesús, ten piedad de nosotros”.

${ }^{30}$ Ver W. Kałamarz, W poszukiwaniu pierwotnej melodii-najstarsze, śpiewnikowe wersje melodyczne "Gorzkich żali” (trad. Buscando la melodia original - las más antiguas versiones melódicas para cantar de los Arrepentimientos amargos), [en:] Perty muzyki kościelnej: chorat gregoriański i Gorzkie żale (trad. Perlas de la música sacra: el Canto gregoriano y Arrepentimientos amargos), ed. R. Tyrała, Kraków 2007, pag. 94 (Pro Musica Sacra, 7). 
tradición de la Iglesia en Polonia encontraremos también una gran colección de cantos de la pasión, frecuentemente de origen popular, pero que ayudan de forma excelente a crear el clima del Viernes Santo. Ellos constituyen no sólo un enorme patrimonio de la tradición, sino que son cantados con gusto por los fieles actualmente.

\section{Vigilia Pascual}

Es obvio, y lo destaca el documento vaticano, que:

la completa celebración de la vigilia pascual se desarrolla de noche; debe comenzar después del inicio de la noche o terminar antes del alba del domingo. Esta regla se debe interpretar en sentido estricto. Los abusos y las costumbres contrarias, que a veces se producen, como anticipar la hora de la celebración de la vigilia pascual a las horas en que por lo general se celebran las misas pre-festivas del domingo, no se pueden admitir $^{31}$.

El canto más importante de esta liturgia es obviamente el Pregón pascual que narra la historia de la salvación ${ }^{32}$. El diálogo a través de la lectura de los fragmentos de la sagrada Escritura del Antiguo y Nuevo Testamento, viene integrado con el canto de los salmos responsoriales ${ }^{33}$. Parece muy importante en este contexto la afirmación que "se evite con atención introducir canciones populares en lugar de los salmos" ${ }^{34}$. Obviamente, según la costumbre, terminadas las lecturas del Antiguo Testamento se canta el himno Gloria a Dios ${ }^{35}$. Pero después de las lecturas del Nuevo Testamento tiene lugar un momento muy importante de la liturgia que se refiere al canto.

El sacerdote entona tres veces el "Alleluia", alzando la voz cada vez más alto, mientras el pueblo a su vez lo repite. Si es necesario, el salmista o un cantor entona el "Alleluia", que el pueblo prosigue intercalando la aclamación entre los versículos del salmo $117^{36}$.

\footnotetext{
${ }^{31} \mathrm{LO} 78$.

32 Ver LO 84.

33 Ver LO 85-86.

${ }^{34} \mathrm{LO} 86$.

${ }^{35}$ LO 87.

${ }^{36}$ LO 87.
} 
Una parte muy importante de la celebración de la Vigilia Pascual esta formada por la liturgia bautismal. Cuando después de la bendición del agua bautismal y la renovación de las promesas bautismales, sigue la aspersión de los fieles con la nueva agua santa, todos los fieles deberían cantar la antífona Vidi aquam o bien otro canto de carácter bautismal ${ }^{37}$. El legislador recomienda no celebrar con prisa la liturgia eucarística que sigue después de todos estos ritos. El sacerdote que preside la liturgia debería utilizar la oración eucarística primera, segunda o tercera "cantada" ${ }^{8}$. En el documento vaticano se sugiere también que "en la comunión es oportuno cantar el salmo 117 con la antífona "Cristo nuestra pascua», o el salmo 33 con la antífona "Alleluia, alleluia, alleluia», u otro canto de júbilo pascual" 39 . La liturgia de la Vigilia Pascual debe ser realizada

con el fin de poder ofrecer al pueblo cristiano la riqueza de los ritos y de las oraciones; es importante que sea respetada la autenticidad de los signos, que se favorezca la participación de los fieles, que esté asegurada en la celebración la presencia de los ministros, de los lectores y de la "schola" de los cantores ${ }^{40}$.

En la catedral de Wawel durante la aspersión de los fieles cantamos un antiguo canto polaco $A$ través del gran don del santo Bautismo ${ }^{41}$. Después, para la procesión con las ofrendas, el coro canta Alleluia, alabad al Señor en su templo de Michał Woźny, y después los fieles siguen con el canto Ha resucitado Cristo, el Señor ${ }^{42}$. Durante la procesión de la comunión el coro canta polifónicamente la antífona

37 Ver LO 89.

${ }^{38}$ LO 91.

${ }^{39}$ LO 91.

${ }^{40} \mathrm{LO} 93$.

${ }^{41}$ El canto $A$ través del gran don del santo bautismo - el autor del texto es I. Świda, de la melodía Roman Dwornik. El canto aparece en el cantoral Alleluja publicado por don Józef Zawitkowski (Warszawa 1978). El texto del canto es el siguiente: "A través del gran don del santo bautismo, oh Cristo, de Tu generosidad has dado a Tus hijos el tesoro de la fe, esperanza y amor. A la Santísima Trinidad, desde los corazones ardientes queremos ofrecer honor eterno. Prometamos velar por la fe, queramos vivir y morir en la misma; Que tus fieles edifiquen tu Iglesia en el mundo, que gobierne en nuestra Patria por largos milenios”.

${ }^{42}$ El canto Ha resucitado Cristo el Señor - el texto Surrexit Christus hodie proviene del siglo XIV, la traducción polaca se remonta al siglo XVI. El texto polaco con la melodía diferente de la que se usa hoy está presente en el Cantoral sacro de don Michał M. Mioduszewski CM (Cracovia 1838). La melodía usada hoy aparece en el Cantoral que contiene los cantos sacros de don Jan Siedlecki (Cracovia 1878). Este es el texto del canto: "Hoy Cristo ha resucitado. ¡Alleluia, Alleluia! Ha dado la alegría a su pueblo. ¡Alleluia, Alleluia! No ha escatimado su vida. ¡Alleluia, Alleluia! Por la extrema miseria humana. ¡Alleluia, Alleluia! En aquel día 
de la comunión de la Vigilia Pascual Temprano, por la mañana de A. Griesbacher, a continuación los fieles interpretan el canto No conoce la muerte el Señor de la $v i d a^{43}$. Durante la procesión de resurrección que consiste en llevar el Santísimo Sacramento con la insignia de Cristo Resucitado tres veces alrededor de la iglesia cuando suena la campana de Segismundo (del siglo XVI), cantamos en especial con los fieles los cantos: Un día alegre ha amanecido para nosotros ${ }^{44}$, Vencedor de la muerte $e^{45}$, Secad las lágrimas, los que lloráis ${ }^{46}$. Todos se refieren al tema de la resu-

de Pascua. ¡Alleluia, Alleluia! Alabemos juntos al Señor. ¡Alleluia, Alleluia! Confesamos a la Santa Trinidad. ¡Alleluia, Alleluia! Damos gloria y honor a Dios. ¡Alleluia, Alleluia!”.

${ }^{43}$ El canto No conoce la muerte el Señor de la vida - el texto se remonta a finales del siglo XVII, su autor es Franciszek Karpiński. La melodía usada actualmente, definida como cracoviana, aparece en el Cantoral que contiene los cantos sacros de don Jan Siedlecki, Cracovia 1895. Este es el texto del canto: "No conoce la muerte el Señor de la vida, aunque ha atravesado sus puertas. Ha arrancado las ligaduras de la tumba la mano santa. ¡Alleluia! Tu deuda, Adán, está saldada, el rescate de la humanidad está pagado. Entrarás en el cielo con tus hijos felices. ¡Alleluia! En vano, guardias, vigiláis la tumba, ya no le encontraréis. Se ha levantado, ha atravesato los muros rocosos".

${ }^{44}$ El canto Un día alegre ha amanecido para nosotros - el texto y la melodía del canto están presentes en el Cantoral sacro de don Michał M. Mioduszewski CM (Cracovia 1838). El texto, sin embargo, proviene del siglo XVII en cambio la melodía del siglo XVI. Estas son las primeras estrofas del canto: "Un día alegre ha amanecido para nosotros, que ninguno de nosotros esperaba, aquel día resucitó Jesús. ¡Alleluia, alleluia! El Rey del cielo ha venido a encontrarnos, como una flor estupenda ha florecido, después de la muerte se nos apareció. ¡Alleluia, alleluia! Ha derrotado a las fuerzas del maligno, ha pisado a los enemigos, ha tenido piedad de los pobres. ¡Alleluia, alleluia! Hasta el tercer día que vivimos, donde consolaba a los santos padres, después les mandó que le siguieran. ¡Alleluia, alleluia! Los que vivían en las profundidades, llorando desde allí gritaban, cuando vieron al Salvador: ¡Alleluia, alleluia!”.

45 El canto Vencedor de la muerte - el texto y la melodía de este canto se pueden encontrar en el Suplemento del Cantoral sacro de don Michał M. Mioduszewski CM (Cracovia 1842). El texto del canto se presenta de la forma siguiente (las primeras estrofas): "Vencedor de la muerte, del infierno y de Satanás sale del sepulcro al tercer día por la mańana. El pueblo infiel se asusta, tiene miedo del milagro de Jonás. ¡Alleluia! La tierra tiembla, se confunden los guardias del sepulcro, el ángel baja, consuela a las mujeres: «Mirad - dice así - el sepulcro está vacío, el Señor ha resucitado de entre los muertos». ¡Alleluia! Huid ansias y tristezas, cuando el Señor Salvador triunfa en la gloria. Ha escuchado la voluntad de su Padre, a nosotros nos da alegría. ¡Alleluia!”.

${ }^{46}$ El canto Secad ya las lágrimas, vosotros que lloráis - el texto y la melodía aparecen en el Cantoral que contiene los cantos sacros de don Jan Siedlecki (Cracovia 1878). El texto del canto Secad ya las lágrimas, vosotros que lloráis es el siguiente: "Secad ya las lágrimas, vosotros que lloráis, sacad fuera la tristeza del corazón todos los que creéis en Cristo, alegraos, regocijaos, porque ha resucitado por su propio poder, como lo había predicho. Alleluia, alleluia, que resuene: „AAlleluia”! En vano los Hebreos pusieron una gran piedra ante el sepulcro, en vano 
rrección del Señor Jesús. Regresando al altar después de la procesión (alrededor de la catedral) cantamos solemnemente Te Deum laudamus ${ }^{47}$ que viene interpretado por el coro alternando con los fieles. Después de la bendición y la palabra de conclusión del cardenal, cantamos la antífona Regina coeli laetare ${ }^{48}$, y después el coro canta el alleluia de la II parte del oratorio Messia di Georg Friedrich Haendel.

\section{El Día de Pascua}

El mismo día de Pascua aparece el segundo formulario de la misa (no el de la vigilia, sino del día). Los textos que había de esta misa, a partir del siglo X, se ampliaban de modo neumático, es decir aparecían tropos y secuencias. Después del Concilio de Trento quedó una secuencia, cantada hasta ahora, Victimae paschali laudes. Su autor es Wipo de Burgundia (murió en 1046) ${ }^{49}$.

El domingo, que es el día de la Resurrección del Señor, se debería poner en relieve por medio de dos elementos litúrgicos específicos. Se trata de llevar a cabo en el ámbito del acto penitencial la aspersión del agua bendita. "Durante la aspersión se canta la antífona "He aquí el agua», u otro canto de carácter bautismal" 50 . El segundo elemento litúrgico importante para vivir el día de Pascua son, según el documento vaticano sobre la „celebración de las fiestas pascuales”, las vísperas bautismales. El documento constata:

Que se conserve, donde está en vigor, o se instaure si es posible, la tradición de celebrar el día de pascua las vísperas bautismales, durante las cuales con el canto de los salmos se hace la procesión a la fuente bautismal ${ }^{51}$.

los guardias armados buscaron la seguridad. No sirvieron de nada los guardas y el sello sobre la tumba del Señor. Dios omnipotente, Dios más alto que todas las criaturas. Se levanta de la tumba, rompe las paredes, no conoce ningún obstáculo. Asustados los guardias caen y casi no pueden controlarse".

${ }^{47}$ Te Deum laudamus - el texto proviene del siglo IV. Hoy en día se atribuye a Niceto di Remesiana. En Polonia cantamos este himno con la traducción de don Tadeusz Karyłowski SJ, con la melodía de don Antoni Chlondowski SDB.

${ }^{48}$ En la tradición polaca existe también la versión en lengua polaca muy popular y cantada con gusto por los fieles. La antífona Regina coeli laetare - el texto de ests antífona mariana proviene del período entre los siglos IX y XII. Por lo general se atribuye a Gregorio V, siglo $\mathrm{X}$ (?). La melodía se remonta al siglo XIII, sin embargo la versión actual fue elaborada en el siglo XVII.

${ }^{49}$ Ver B. Nadolski, Liturgika, pág. 72.

${ }^{50} \mathrm{LO} 97$.

${ }^{51}$ LO 98. 
Desde el siglo $\mathrm{X}$ se celebraban estas vísperas con la participación de los neo-bautizados que con el canto del salmo 92 iban en procesión a la fuente.

En la fuente bautismal se cantaban el salmo 113 y el Magnificat. A continuación la procesión se dirigía hacia la capilla de la Santa Cruz con el canto del Vidi aquam. Al final se servía a los participantes tres clases de vino en los pórticos de la capilla ${ }^{52}$.

\section{Conclusiones}

\section{La Música litúrgica en la reflexión sobre el Misterio Pascual}

Si "la música constituye la parte integral de la liturgia solemne" (KL 112), es muy importante que durante las celebraciones más importantes en el templo, y especialmente durante las celebraciones litúrgicas, ella se convierta en un signo muy comprensible, transparente. Cuando de hecho preparamos la música litúrgica, debemos tomar siempre en consideración: el año litúrgico, es decir el período, la solemnidad o recuerdo, nos centramos en el contenido de la antífona de la misa en referencia a los cantos de entrada y de la comunión), el formulario de la misa, el contenido de la colecta y de las lecturas de la misa, especialmente el Evangelio. Todos estos valores y contenidos de las oraciones y de las lecturas litúrgicas contempladas deben verse reflejados en la música que se propone para una celebración concreta. Ahí radica su integralidad: no es un simple complemento, añadido, substitución, entretenimiento musical, sino que es idéntica que la liturgia, está relacionada con la misma de forma indisoluble, intrínseca. Fluye de la misma y a ella conduce. La enriquece, la embellece y constituye su signo más comprensible.

No ocurre de forma distinta con la música durante el Triduo Pascual. Esta música debe ponderarse mucho más, porque nos encontramos con el punto culminante del año litúrgico, la fiesta de Cristo sufriente, crucificado y resucitado. Es el acontecimiento salvífico más importante que celebramos en ese momento. Hacia el gran significado y expresividad de estos días santos del Triduo Pascual llamó nuestra atención el papa Benedicto XVI durante la audiencia general del

52 B. Nadolski, Liturgika, pág. 72. 
19 de marzo de 2008. Que estas palabras sean una conclusión particular de mi intervención. El Santo Padre dijo:

Los próximos tres días se llaman comúnmente "santos" porque nos hacen revivir el evento central de nuestra Redención; nos reconducen de hecho al núcleo esencial de la fe cristiana: la pasión, la muerte y la resurrección de Jesucristo. Son días que podemos considerar como un único día: constituyen el corazón y el punto de apoyo de todo el año litúrgico, así como de la vida de la Iglesia. [...] Recordar los misterios de Cristo significa también vivir en profunda y solidaria adhesión al hoy de la historia, convencidos que todo lo que celebramos es una realidad viva y actual. [...] Estos días renuevan en nosotros la gran esperanza: Cristo crucificado ha resucitado y ha vencido al mundo. El amor es más fuerte que el odio, ha vencido y debemos asociarnos a esta victoria del amor. Así que debemos recomenzar desde Cristo y trabajar en comunión con Él por un mondo fundado en la paz, en la justicia y en el amor ${ }^{53}$.

\section{Summary}

\section{La Música litúrgica en la reflexión sobre el Misterio Pascual}

If "the music is an integral part of the solemn liturgy" (SC 112) it is tremendously important that during the crucial ceremonies at churches, particularly those involving liturgical celebrations, it would become its clear sign. Since, when we prepare liturgical music we always draw our special attention to: liturgical year, namely, to a particular season, feast or celebration, examining the contents of the holy mass antiphon (referring to entrance songs and the holy communion), the mass order, the collect and the readings, especially the Gospel. And this entire content of liturgical prayers and readings is to be reflected through music of the celebrations. Therefore the music becomes integral because its role is not merely supplementary, complementary, substitutive nor decorative, but incorporated in liturgy with which it is inextricably linked. Music springs from liturgy and leads to liturgy. It enriches mass liturgy, makes it more grandly and clearly rendered.

It should be no different during the Easter Triduum for which the music ought to be even more thoroughly prepared as for the most important season of the liturgical year, that is, the Feast of Christ, suffering, crucified and resurrected.

53 Benedetto XVI, Udienza Generale, (19 03. 2008), www.vatican.va/holy_father/benedict_ xvi/audiences/2008/documents/hf_bennxvi_aud_20080319_it.html (dostęp: 15.02.2014). 
As it is the greatest event of the mystery of redemption observed here and now. The importance of the Easter Triduum was indicated by Pope Benedict XVI during his General Audience on 19 March 2008. May his words serve as the conclusion of my speech:

These three days are commonly known as 'holy' because they allow us to re live the event central to our Redemption. They lead to nucleus of Christian faith: the passion, Heath, and resurrection of Jesus Christ. These three days could be considered as one single day. They make up the heart and are the key to both the liturgical year and the life of the Church. ... Remembering the mysteries of Christ also means a willing and complete adherence to the history of today, convinced that when we celebrate, it is vivid and present reality... These holy days reawaken a great hope in us: Christ was crucified, yet he rose again and conquered the world. Love is stronger than hate, it has triumphed and we should affiliate ourselves with this victory of love. We should therefore start again from Christ and work together with him for a world founded on peace, justice and love ${ }^{54}$.

Palabras claves música litúrgica, Triduo Pascual, cantos del coro y de los hermanos legos durante el Triduo, Misa de la Cena del Seńor, Liturgia de la Pasión, Vigilia Pascual

Keywords liturgical music, Paschal Triduum, choir singing and lay brother's singing, Mass of the Lord's Supper, Liturgy of the Passion, Easter Vigil

\section{Bibliografía}

Benedykt XVI, Udienza Generale, (19 03. 2008), www.vatican.va/holy_father/benedict_ xvi/audiences/2008/documents/hf_ben-xvi_aud_20080319_it.html

Congregatio pro Culto Divino, Letterae circulares Paschalis sollemnitatis. De festis paschalibus praeparandis et celebrandi (16 I 1988), „Notitiae” 24 (1988), pag. 81-107.

Congregación para el Culto Divino, Carta circular dada en la sede de la Congregación para el Culto Divino y la Disciplina de los Sacramentos La preparación y celebración de las fiestas pascuales, www.aciprensa.com/Docum/documento.php?id=95.

Nadolski B., Liturgika, t. 2, Liturgia i czas, Poznań 1991.

${ }^{54}$ Benedict XVI, Udienza Generale, (19 03. 2008) www.vatican.va/holy_father/benedict_xvi/ audiences/2008/documents/hf_benxvi_aud_20080319_it.html (15.02.2014). 